\title{
Magnitude and timing of inbreeding depression in a diploid population of Epilobium angustifolium (Onagraceae)
}

\author{
B. C. HUSBAND* \& D. W. SCHEMSKE \\ Department of Botany, University of Washington, Seattle, Washington 98195, U.S.A.
}

\begin{abstract}
Evolutionary theory predicts a negative correlation between the rate of self-fertilization and the magnitude of inbreeding depression in natural plant populations. We examined the mating system and inbreeding depression at four life stages in a diploid population of Epilobium angustifolium (Onagraceae). The multilocus rate of self-fertilization, inferred from the segregation of allozymes at two polymorphic loci (Pgi-2, Mdh-2) among seedlings from 22 open-pollinated plants, was 0.06 $(\mathrm{SE} \pm 0.10)$. However, after adjusting for differential mortality of selfed progeny prior to the seedling stage, the selfing rate was 0.45 . The parental inbreeding coefficient $(F)$ was -0.26 $(\mathrm{SE} \pm 0.103)$ indicating more heterozygotes than in a randomly mating population. The magnitude of inbreeding depression at seed maturation, seed germination, juvenile survival and dry mass at 8 weeks was measured in a greenhouse experiment. Thirty-four plants, grown from open-pollinated seed, were each self-fertilized and randomly outcrossed. We observed significant inbreeding depression at all four stages, although its magnitude differed significantly among maternal plants and among stages. Inbreeding depression was largest during seed maturation $(0.87)$, where seed-set in outcrossed flowers (65.7 per cent) was eight times higher than in selfed flowers ( 8.3 per cent). Inbreeding depression for dry mass after 8 weeks $(0.50)$ was at least twice that for germination (0.25) and survival (0.15). The magnitude of inbreeding depression for each of the 34 maternal parents was not significantly correlated across life stages, suggesting that its genetic basis varies across the life cycle. Our results indicate that $E$. angustifolium exhibits high levels of inbreeding depression, much of which is expressed early in the life cycle, during seed maturation, consistent with results for other long-lived, outcrossing species. However, given its moderate rate of self-fertilization, the total inbreeding depression (0.95) maintained in E. angustifolium is very high in comparison to other angiosperms.
\end{abstract}

Keywords: Epilobium angustifolium, family variation, inbreeding depression, isozymes, life stage, mating system.

\section{Introduction}

Inbreeding depression, the reduced fitness of progeny derived from inbreeding relative to outbreeding, is an important selective force governing the evolution of plant sexual systems (Darwin, 1876; Lloyd, 1979; Charlesworth \& Charlesworth, 1979, 1987; Lande \& Schemske, 1985). Recent interest in the detrimental effects of inbreeding stem from the theoretical premise that inbreeding depression will evolve in association with the breeding history of a population, and that the rate and direction will be determined partly by its genetic basis (Lande \& Schemske, 1985; Charlesworth

*Correspondence: Department of Botany, University of Guelph, Guelph, Ontario, Canada N1G 2W1.
\& Charlesworth, 1987; Charlesworth et al., 1990). If inbreeding depression is the result of lethal or sublethal deleterious recessive alleles, as is commonly believed, it will be high in populations that are historically outbred and heterozygous; however, in inbred populations, inbreeding depression will be low since recessive mutations will be continually exposed as homozygotes and purged through selection (Lande \& Schemske, 1985).

The number of estimates of the magnitude of inbreeding depression for natural populations has increased dramatically in the last decade (Schemske, 1983; Schoen, 1983; Charlesworth \& Charlesworth, 1987; Dudash, 1990; Ashman, 1992; Johnston, 1992; see Husband \& Schemske, 1995, for additional references). While collectively they provide good 
support for the negative correlation predicted between inbreeding depression and selfing rate (Husband \& Schemske, 1995), there are still relatively few studies that relate inbreeding depression to the mating system or to other measures of the history of inbreeding (Toppings, 1989; Holtsford \& Ellstrand, 1990; Parker et al., 1995). Furthermore, most studies have focused on the magnitude of inbreeding depression at the level of the population and relatively little attention has been paid to the timing of inbreeding depression through the life cycle or to variation in its magnitude among plants within populations, both of which have a direct bearing on the potential for the evolution of inbreeding depression.

Evolutionary theory has not yet adequately considered how inbreeding depression should be distributed among stages or among individuals within populations or whether these attributes will be influenced by shifts in the mating system. Clearly, there are strong reasons why one would expect such variation to exist. In self-compatible species, individuals will differ in their inbreeding histories and thus in the number of deleterious alleles sheltered from selection (Haldane, 1949; Kimura, 1958). Therefore, one would expect variation in inbreeding depression among parents, on which selection may act. Variation in the magnitude of inbreeding through the life cycle depends on the extent to which selection is stage-specific and on the genetic correlations and the genetic basis of inbreeding depression among life stages. If the genes causing inbreeding depression are expressed across stages, we would expect a correlation in the magnitude of inbreeding depression at different stages (Ägren \& Schemske, 1993; Husband \& Schemske, 1995). Several studies have reported variation in inbreeding depression among parents and among life stages (Schemske, 1983; Dudash, 1990; Johnston, 1992), but rarely are the numbers of families and sample sizes within families sufficient for this to be adequately quantified. In addition, past analyses were incorrect in that they lacked the appropriate transformation to examine differences in relative fitness among parents (Johnston \& Schoen, 1994).

In this paper we present the results of a study designed to estimate the mating system and the magnitude and timing of inbreeding depression in a single population of the herbaceous perennial Epilobium angustifolium L. (= Chamaenerion angustifolium (L.) Scop.). The genus Epilobium consists of approximately 162 species that exhibit a wide range of breeding systems, from predominantly outcrossing to high autogamy (Raven, 1979, 1988). Like all members of the genus, $E$. angustifolium is self-compatible, but because the flowers are large, protandrous and insect-pollinated, it is likely to be highly outcrossed, although the multiflowered reproductive stems would allow for some geitonogamy. We estimated the selfing rate using genetic markers and the magnitude of inbreeding depression at each of four life history stages based on self and outcross pollinations carried out on each of 34 plants. Our study addresses the following questions. (1) What is the magnitude of inbreeding depression in the population and is it consistent with that predicted by the mating system? (2) Is there variation among families in the magnitude and timing of depression? (3) Is inbreeding depression distributed uniformly throughout the life cycle? (4) Is the magnitude of inbreeding depression in each maternal parent correlated across the life stages?

\section{Materials and methods}

\section{Study site}

E. angustifolium seed was collected from a diploid population (D2) along the Beartooth Pass in Montana, $24.5 \mathrm{~km}$ southwest of Red Lodge. Both diploid and tetraploid cytotypes have been described for this species (Mosquin, 1967). This population was initially identified as diploid by Flint $(1980)$ and this was confirmed prior to this study by additional chromosome counts and a survey of DNA content in 28 individuals using flow cytometry (Schemske \& Husband, unpubl.).

\section{Mating system}

The mating system, measured as the rate of self-fertilization $\left(r_{\mathrm{m}}\right)$, was estimated from the segregation of protein allozymes in progeny from 22 open-pollinated plants, collected at random from the population in September 1991. Following germination, seedlings were planted into individual pots and grown to the 4-10 leaf stage. Family sizes at this time ranged from 5 to 18 progeny (mean 7.5).

Each seedling was scored at two isozyme loci using horizontal starch gel electrophoresis. Young leaves were ground in a $0.1 \mathrm{M}$ Tris buffer $(\mathrm{pH} 7.5)$ containing sodium bisulphite, sucrose and PVP-40; the homogenate was absorbed onto $3 \times 6 \mathrm{~mm}$ paper chromatography wicks and inserted into a starch gel. Polymorphic loci for each of the enzymes phosphoglucose isomerase (PGI) and malate dehydrogenase (MDH) were resolved on Tris-borate $(\mathrm{pH} 8)$ and histidine-citrate ( $\mathrm{pH} 6)$ buffer systems, respectively (Soltis et al., 1983). The tris-borate gel (12 per cent w/v starch) was run at $50 \mathrm{~mA}$ and $300 \mathrm{~V}$ for $6 \mathrm{~h}$ while the histidine-citrate gel (13.5 per cent starch) was run at $50 \mathrm{~mA}$ and $325 \mathrm{~V}$ for $6 \mathrm{~h}$. Segregation patterns were

(c) The Genetical Society of Great Britain, Heredity, 75, 206-215. 
observed in family-structured data and were consistent with simple Mendelian inheritance.

The multilocus selfing rate and the mean singlelocus selfing rate were estimated using the mixedmating model based on the method of Ritland \& Jain (1981) and Ritland (1989), which uses a maximum likelihood procedure to infer the genotypes of the maternal parents, the frequencies of alleles in the pollen pool $(p)$, and the proportion of progeny per family that are derived from outcrossing $(t)$. The maternal genotypes were inferred using the algorithm of Brown \& Allard (1970). Standard errors for each selfing rate estimate were generated using a bootstrapping procedure in which 22 progeny arrays were sampled, with replacement, 100 times.

The primary selfing rate $(r)$, the selfing rate at the time of fertilization, was estimated by adjusting the measured selfing rate $\left(r_{\mathrm{m}}=1-t\right)$ for any inbreeding depression that may have occurred before progeny were analysed, i.e. at seed-set and germination, using the formula,

$$
r=\frac{r_{\mathrm{m}}}{\left(1-\delta+r_{\mathrm{m}} \delta\right)},
$$

where $\delta$ is the sum of inbreeding depression measured at seed maturation and germination (Maki, 1993).

The inbreeding coefficient $F$, a measure of the deviation in the frequency of heterozygotes from that in a randomly mating population, was also estimated as an additional measure of inbreeding using the inferred maternal genotypes from the mating system analysis. This parental inbreeding coefficient was estimated as part of the mating system analysis (Ritland, 1989).

\section{Inbreeding depression}

Inbreeding depression was estimated by comparing plants derived from outcrossing and selfing in the greenhouse. Thirty-four plants, one offspring from each of 34 families of open-pollinated seed, were grown and used as maternal parents. For each plant, four flowers were self-fertilized and four were outcrossed with pollen from the 33 remaining plants. Each flower was emasculated and the equivalent of one anther's worth of pollen was applied evenly across each of the four stigma lobes. For outcrossed flowers, a pollen donor was selected at random from the other 33 plants for each stigma lobe. Two additional flowers per plant were emasculated and left unpollinated to check for any inadvertent pollen transfer; none occurred. Since anthesis within an inflorescence as well as on different plants is asynchronous, a selfed and outcrossed pair of flowers was pollinated on each plant every second day provided there were at least 15 potential donors. Fruit were collected as they began to dehisce, about 2-3 weeks after pollination.

The effects of inbreeding were estimated at four life stages: seed maturation, seed germination, survival to 8 weeks, and dry mass at 8 weeks. Seed maturation was measured in each of the eight fruits per maternal plant as the number of filled seeds, expressed as a proportion of the number of ovules (seed set). To do this, seeds were classified as either filled, or not. Filled seeds were round in cross-section and, in preliminary trials, germinated with frequency greater than 80 per cent ( $n=100$ seeds). Unfilled seeds were either aborted or unfertilized. In an additional inbreeding depression study on the same population (Husband \& Schemske, 1995), an average of three per cent of the ovules per fruit were 'presumed unfertilized' based on their size and uniformity, indicating that pollen quantities were sufficient and that prefertilization events had little influence on seed-set.

Twenty filled seeds from each of the eight fruits per plant were placed in a petri dish on filter paper. If fewer than four fruits matured for any pollination treatment, seeds were randomly collected from the existing fruits. After 4 weeks at $4^{\circ} \mathrm{C}$, the filter paper was wetted and the dishes placed in an incubator $\left(12 \mathrm{~h}\right.$ day $/$ night; $25^{\circ} \mathrm{C}$ day $/ 21^{\circ} \mathrm{C}$ night). The germinating seeds were counted and removed weekly, starting 1 week after sowing, until germination ceased.

One week after sowing seeds, 10 selfed and 10 outcrossed seedlings from each parent were transplanted into $5 \mathrm{~cm}$ pots and, once at the rosette stage, transplanted again into $2 \mathrm{~L}$ square pots. In addition, a randomly chosen outcrossed seedling was placed in the opposite corner of each pot as a competitor. Because we expected the population to be primarily outcrossing, seedlings in natural conditions would be competing more often with outcrossed than with selfed individuals. Any target or competitor seedling dying within the first week was replaced. Pots were then randomly arranged in a $25 \times 28$ array, and pots containing two dummy plants were placed in any empty cells and around the periphery to reduce edge effect. All target plants were harvested after 8 weeks, by which time 419 plants ( 73 per cent) had flowered. To determine if there was competition between the target plants and their competitors, we also harvested the competitors from 50 pots containing selfed progeny and 50 with outcrossed progeny. We then calculated the correlation between the dry mass of targets and their competitors. A negative correlation would suggest that plants were competing for resources. All plants were dried at $60^{\circ} \mathrm{C}$ for $48 \mathrm{~h}$ and then weighed.

Cumulative fitnesses for self and outcross progeny from each maternal parent were calculated as the product of mean fitnesses from seed-set, germination, 
survival and dry mass. Population-level inbreeding depression $(\delta)$ was then estimated as:

$$
\delta=1-\frac{w_{\mathrm{sp}}}{w_{\mathrm{op}}}
$$

where $w_{\mathrm{sp}}$ and $w_{\mathrm{op}}$ are, respectively, the mean fitnesses of selfed and outcrossed progeny calculated from the means of each cross-type for each maternal parent. This estimate is similar to Johnston \& Schoen's (1994) $\delta_{p}$, in that it is calculated as a ratio of the mean fitnesses for selfed and outcrossed progeny rather than a mean of the family-specific ratios. We calculated the population means for selfed and outcrossed progeny by averaging the mean fitness values calculated at the family level. This was done so that each family, which differed in number of progeny because of variation among families in inbreeding depression, was weighted equally in the final population estimate. A confidence interval for the population estimate of inbreeding depression, discussed in Johnston \& Schoen (1994), was calculated following Miller (1986).

A mixed model ANOVA was used to quantify the effect of pollen source (fixed effect) and family (random effect) on seed-set, percentage germination and dry mass at 8 weeks. When necessary, variables were transformed to meet the assumptions of normality and homoscedasticity (Sokal \& Rohlf, 1981). To determine whether inbreeding depression differed among maternal plants, we also tested for a significant interaction between pollen treatment and maternal parent after a log-transformation of all data. With this transformation a significant pollen treatment $\times$ maternal parent interaction reflects differences among parents in the relative effects of selfing and outcrossing (Johnston \& Schoen, 1994). The effect of pollination treatment on seedling survival was examined using a $G$-test of independence. Heterogeneity among maternal plants in this respect was not examined since family sample sizes were often not large enough. Mean cumulative fitnesses for selfed and outcrossed progeny in each family were compared using a Mann-Whitney test (Sokal \& Rohlf, 1981). Correlation among families between the mean fitness of selfed and outcrossed progeny was calculated by a Spearman's rank correlation.

The effects of self-fertilization on different stages of the life cycle were compared using a repeated measures MANOVA with log (seed-set), log (germination), log (survival) and $\log$ (dry mass) as dependent variables and cross-type and family as independent variables. Because the number of selfed and outcrossed progeny varied widely among families and stages, we used family means for selfed and outcrossed progeny, at each stage, for this analysis. In addition, a Spearman's rank correlation between the family-level inbreeding depression estimate for each of the six pair-wise stage combinations was calculated to determine whether inbreeding depression in different stages was related.

One difficulty with studies of variation in inbreeding depression among stages is that inbreeding depression estimates for later stages are necessarily based on only those progeny that survived all previous stages. Since it is assumed that mutations segregate independently among the offspring, late inbreeding depression as measured in surviving offspring should in most cases be representative of the family. Only those mutations which have a lethal effect and which are expressed both early and late will not be accounted for in the estimate of late inbreeding depression. This may result in a downward bias in the estimates of late inbreeding depression and in the correlations between early and later stages.

\section{Results}

\section{Mating system}

The multilocus selfing rate $\left(r_{\mathrm{m}}\right)$ estimated for this population of $E$. angustifolium was 0.06 ( $\mathrm{SE} \pm 0.10 ; 22$ families; 7.5 progeny per family), a value not significantly different from zero $(t=0.60, P>0.05)$. The multilocus estimate was based on two polymorphic loci (allele frequencies: Pgi-2 0.55/0.23/0.07/0.06/0.04/ $0.03 / 0.02 ; M d h-20.58 / 0.42)$. Seven Pgi-2 allozymes were present in the population. Since the selfing rate estimation program can only accommodate three allozymes per locus, the five least frequent allozymes were collapsed into a single frequency (allele frequencies $0.55 / 0.23 / 0.22)$. The mean of the singlelocus estimates was 0.08 ( $\mathrm{SE} \pm 0.11$ ); the difference between single-locus and multilocus estimates (mean difference $=0.011, \mathrm{SE} \pm 0.034$ ) was not significantly different from zero $(t=0.32, P>0.05)$.

The primary selfing rate $(r)$ for this population of $E$. angustifolium is 0.45 . That is, at the time of fertilization 45 per cent of the ovules were self-fertilized.

The parental inbreeding coefficient $(F)$ based on two isozymes was -0.26 ( $\mathrm{SE} \pm 0.103$ ), less than the expected $F=0$ for a randomly mating population. This estimate indicates there was an excess of heterozygotes in the population relative to that expected in a randomly mating population.

\section{Inbreeding depression}

On average, the effect of selfing was significantly different from outcrossing for all four life stages examined (Tables 1 and 2) and for the cumulative effects of all stages (Mann-Whitney, $\left.U_{32}=16, P<0.0001\right)$. Seed 
set was 87 per cent lower in self-fertilized flowers than in outcrossed flowers. Germination of progeny from selfed flowers (hereafter, selfed progeny) was 25 per cent lower than outcrossed progeny. Eighty-one per cent of selfed progeny (range 20-100 per cent) survived the 8 week growing period compared to 95 per cent (range 40-100 per cent) of outcrossed progeny $(330$ plants per pollination treatment; $\left.G_{1}=32.6, P<0.001\right)$. Of the survivors, 54 per cent of the selfed progeny and 88 per cent of the outcrossed progeny flowered. Dry mass after 8 weeks was 50 per cent lower in selfed progeny than in outcrossed progeny. In addition, a strong negative correlation between dry mass of target plants and competitors $\left(r_{\mathrm{s}}=-0.71, \quad P<0.001, \quad n=100\right)$ indicated that competition was an important determinant of dry mass in the greenhouse experiment. When the data for seed set, germination, survival and dry mass at 8 weeks are combined into a cumulative measure of fitness, selfed progeny were 95 per cent less fit than outcrossed progeny (paired $t$-test: $t_{32}=12.5, P<0.001$ ). In other words, inbreeding depression in this population of $E$. angustifolium averaged 0.945 (upper and lower 95 per cent confidence limits, 0.97 and 0.93 ).

At present there is little censensus as to how population-level measures of inbreeding depression should be

Table 1 Fitnesses of selfed and outcrossed progeny of Epilobium angustifolium and inbreeding depression at four life history stages

\begin{tabular}{lrcrrrr}
\hline Life stage & \multicolumn{2}{c}{$\begin{array}{c}\text { Selfed } \\
\text { progeny }\end{array}$} & \multicolumn{2}{c}{$\begin{array}{c}\text { Outcrossed } \\
\text { progeny }\end{array}$} & $\delta$ (range) \\
\hline Seed-set (per cent) & 8.3 & $(5.0)$ & 65.7 & $(20.4)$ & 0.874 & $(0.46-1.00)$ \\
Seed germination (per cent) & 62.1 & $(22.0)$ & 82.7 & $(11.0)$ & 0.249 & $(-0.13-0.86)$ \\
Survival to 8 weeks (per cent) & 81.2 & $(25.5)$ & 95.2 & $(11.5)$ & 0.147 & $(-0.43-0.80)$ \\
Dry mass at 8 weeks (g) & 3.4 & $(2.0)$ & 6.8 & $(1.7)$ & $0.500(-0.39-0.92)$ \\
Cumulative means & 0.21 & $(0.22)$ & 3.83 & $(1.77)$ & 0.945 & $(0.80-1.00)$ \\
\hline
\end{tabular}

Values are the means (SD) of 34 maternal plants. Cumulative means for selfed and outcrossed progeny are the means of cumulative fitness for 34 maternal parents.

The cumulative fitness of each maternal parent is the product of family means for each life stage (note that seed set, germination and survival are entered as proportions rather than percentages in this calculation). Inbreeding depression $(\delta)$ is calculated as $1-w_{\mathrm{s}} / w_{\mathrm{o}}$, where $w_{\mathrm{s}} / w_{\mathrm{o}}$ is the ratio of selfed and outcrossed fitnesses.

Table 2 Effects of pollination treatment (cross- vs. self-pollination) and maternal parent on performance at four stages of the life cycle in diploid Epilobium angustifolium. Each stage was analysed in a mixed model (maternal parent as random effect) ANOvA . Transformations were applied where necessary (see superscripts to life stages) to reduce heteroscedasticity and deviations from normality

\begin{tabular}{|c|c|c|c|c|}
\hline Life stage & Source of variation & d.f. & SS & $F$ \\
\hline Filled seeds per fruit $(\%) \dagger$ & $\begin{array}{l}\text { Pollination (Poll.) } \\
\text { Maternal Plant (Mat. Plt.) } \\
\text { Poll. } \times \text { Mat. Plt. } \\
\text { Error }\end{array}$ & $\begin{array}{r}1 \\
33 \\
33 \\
289\end{array}$ & $\begin{array}{r}1214363.3 \\
305162.4 \\
115567.6 \\
587445.7\end{array}$ & $\begin{array}{c}346.76^{* * *} \\
4.55^{* * *} \\
1.72^{*}\end{array}$ \\
\hline Germination (frequency) $\neq$ & $\begin{array}{l}\text { Pollination } \\
\text { Maternal Plant } \\
\text { Poll. } \times \text { Mat. Plt. } \\
\text { Error }\end{array}$ & $\begin{array}{r}1 \\
32 \\
32 \\
189\end{array}$ & $\begin{array}{r}4.688 \\
6.717 \\
3.767 \\
11.350\end{array}$ & $\begin{array}{c}39.82^{* * *} \\
3.50^{* * *} \\
1.96^{* *}\end{array}$ \\
\hline Dry mass at 8 weeks ( $\mathrm{g}$ ) & $\begin{array}{l}\text { Pollination } \\
\text { Maternal Plant } \\
\text { Poll. } \times \text { Mat. Plt. } \\
\text { Error }\end{array}$ & $\begin{array}{r}1 \\
32 \\
32 \\
508\end{array}$ & $\begin{array}{r}1324.7 \\
1059.1 \\
687.1 \\
4618.8\end{array}$ & $\begin{array}{r}61.70^{* * *} \\
3.64^{* * *} \\
2.34^{* * *}\end{array}$ \\
\hline
\end{tabular}

${ }^{*} P<0.05 ;{ }^{* *} P<0.01 ;{ }^{* * *} P<0.001$.

$\dagger$ Analysis on ranks.

$\ddagger$ Arcsine square-root transformed. 
calculated from stage-specific data (Agren \& Schemske, 1993; Johnston \& Schoen, 1994; Parker et al., 1995). The estimate of 0.945 was generated by dividing the cumulative fitness of selfed progeny into that of outcrossed progeny and subtracting from one, where cumulative fitnesses were the product of family means at each life stage. The approach used here seems most appropriate since it gives each family, regardless of different initial or final sample sizes, equal weight in the population estimate. One alternative is to estimate the stage-specific fitnesses as the overall mean of all progeny, in which case the population inbreeding depression for our study was 0.957. Inbreeding depression values were also very similar when cumulative fitness was calculated as the product of the self/ outcross ratio at each stage and where stage-specific inbreeding depression values are family means calculated either of two ways: (1) $1-w_{\mathrm{si}} / w_{\mathrm{oi}}[\delta=0.956]$, or (2) if $w_{\mathrm{si}}<w_{\mathrm{oi}}$ then $\delta=1-w_{\mathrm{oi}} / w_{\mathrm{si}}$, if $w_{\mathrm{si}}>w_{\mathrm{oi}}$ then $\delta=w_{\mathrm{oi}} / w_{\mathrm{si}}-1[\delta=0.954]$.

Inbreeding depression was not uniform among life stages. The effects of selfing were greatest at seed-set, where inbreeding depression $(\delta=0.87)$ was 1.7 times higher than for dry mass after 8 weeks and 3.5 and 6 times higher than for germination and juvenile survival, respectively. In the repeated measures MANOVA, the effects of self- versus cross-pollination differed significantly among stages (time $\times$ pollination interaction, Wilks's $\lambda=0.94, P<0.001$ ).

The effect of pollination treatment on seed-set, germination and dry mass differed among maternal plants as indicated by significant pollination treatment $\times$ maternal plant interaction terms in the analysis of variance (Table 2). All interactions remained significant at $P<0.001$ after log-transforming all values, indicating significant variation among maternal parents in the magnitude of inbreeding depression.

Inbreeding depression varied widely among families at each life stage (Table 1). Values at seed-set ranged from 0.46 to 1.0 . This was a product of variation in seed-set upon selfing (Fig. 1) as well as upon outcrossing. One maternal plant set no seed upon selfing. The number of families in which the performance of selfed progeny exceeded that of outcrossed progeny was zero at seed set, three at germination, four at survival and three at dry mass. In addition, correlations between selfed and outcrossed fitnesses among maternal parents were positive for each life stage but the magnitude of the correlation depended on the life-history stage examined. Spearman's rank correlations among selfed and outcrossed treatments were significant at the first two stages, seed set $\left(r_{\mathrm{s}}=0.42, P<0.05, n=34\right)$ and percentage germination $\left(r_{\mathrm{s}}=0.38, \quad P<0.05\right.$, $n=33$ ), but not significant at juvenile survival $\left(r_{\mathrm{s}}=0.24, P>0.10, n=33\right)$ or dry mass at 8 weeks $\left(r_{\mathrm{s}}=0.18, P>0.25, n=33\right)$.

Variation among families for inbreeding depression based on cumulative fitness was narrow compared to stage-specific variation. Inbreeding depression values ranged from 0.81 to 1 . Outcrossed progeny from all families were consistently more fit than selfed progeny; however, whether there were differences among maternal plants could not be evaluated statistically. There was a substantial difference between the variance in cumulative fitness of selfed and outcrossed progeny for the 34 families (Fig. 2). Selfed families exhibited extremely little variation (variance $=5.01$, range $0.2-7.7$ ) in fitness in contrast to outcrossed families $($ variance $=311.8$, range $1.3-79.1$ ). Also, the cumulative fitnesses of selfed and outcrossed progeny were significantly correlated among families $\left(r_{s}=0.58\right.$, $P<0.01, n=33$ ).

Rank correlations of family-level inbreeding depression among all six pair-wise stage combinations were positive. Taken individually, the correlations between inbreeding depression at seed-set and dry mass $\left(r_{\mathrm{s}}=0.39, P<0.05\right)$, and germination and survival $\left(r_{\mathrm{s}}=0.38, P<0.05\right)$ were significant. However, when their significance was evaluated in relation to an experimentwise error rate of 0.0085 , calculated using the Dunn-Sidák procedure (Sokal \& Rohlf, 1981), none of the correlations was significant.

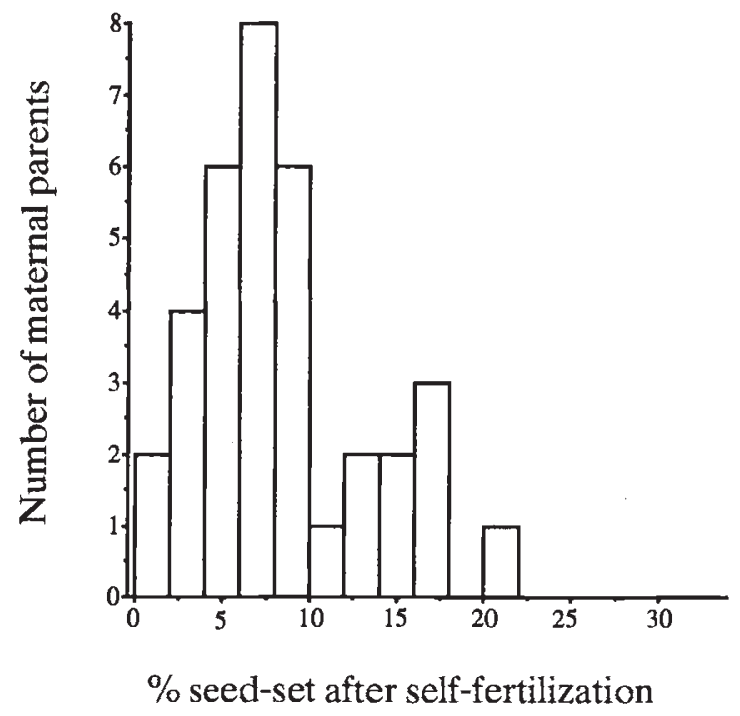

Fig. 1 Distribution of seed-set values upon selfing for 34 maternal plants of Epilobium angustifolium. Seed-set is expressed as a percentage of the fertilized ovules, and is the mean of three to four fruits per plant. 

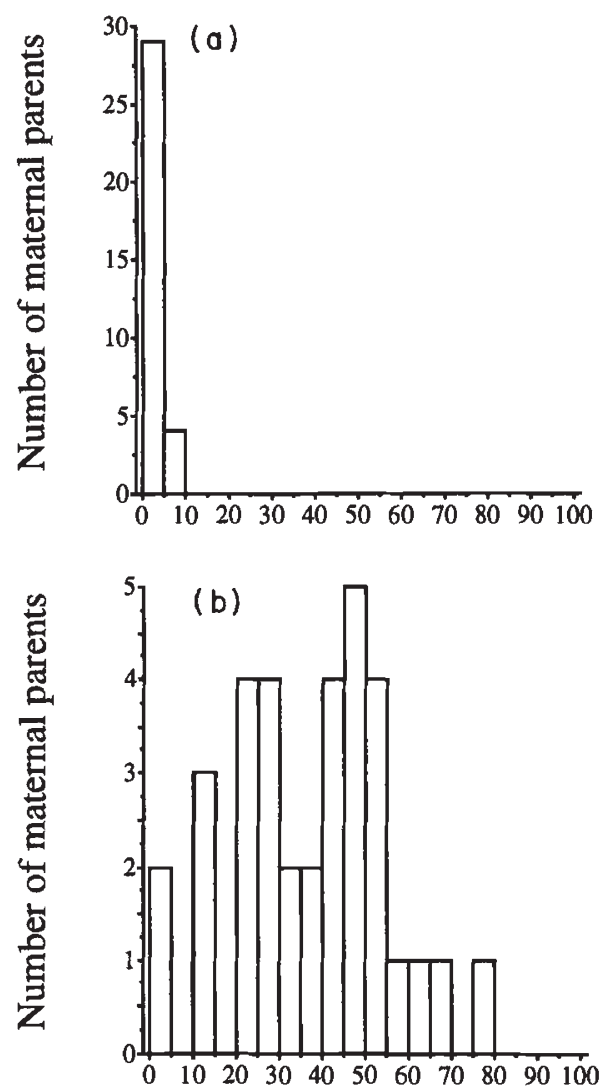

\section{Cumulative fitness of maternal parent}

Fig. 2 Distribution of family cumulative fitness values (based on seed-set, seed germination, survival and biomass) for (a) selfed and (b) outcrossed progeny from 34 maternal plants of Epilobium angustifolium.

\section{Discussion}

In this study, we found that Epilobium angustifolium was highly outcrossed $\left(r_{\mathrm{m}}=0.06\right)$; only six per cent $(\mathrm{SE} \pm 0.10)$ of the seedlings examined were the product of self-fertilization. The inbreeding coefficient also indicated that the population was not inbred $(F=-0.26)$. However, an estimate of the primary selfing rate $(r=0.45)$ indicated that, at the time of fertilization, plants were moderately self-fertilized. The population estimate of inbreeding depression was 0.95 (95 per cent $\mathrm{CI} \pm 0.02$ ); that is, selfed progeny were only five per cent as fit as outcrossed progeny based on comparisons at four life stages. The effects of inbreeding were significant at all stages but the magnitude of inbreeding depression differed among life stages. Inbreeding depression was largest during seed maturation, followed by dry mass, germination and juvenile survival. There were no significant correlations among estimates of inbreeding depression at each stage for the
34 families examined. The effects of inbreeding were significantly different among maternal parents at each stage examined but cumulative inbreeding depression was quite uniform among maternal plants.

The marked difference between the measured $\left(r_{\mathrm{m}}=0.06\right)$ and primary $(r=0.45)$ selfing rates in this species reflects the differential mortality of selfed and outcrossed zygotes that occurs between the time of fertilization and the seedling stage, at which electrophoresis was conducted. While most empirical studies of mating systems have estimated the measured selfing rate, inbreeding depression is best interpreted in the context of the primary selfing rate, on which all theoretical studies are based (Lande et al., 1994). The intermediate selfing rate of $r=0.45$ may be surprising given that flowers in $E$. angustifolium are large and protandrous, and that pollen-collecting bees tend to forage primarily on male-phase flowers, thereby reducing the likelihood of pollen transfer among flowers on the same inflorescence (Galen \& Plowright, 1988). Selfing may be higher as a result of geitonogamous pollinations within inflorescences and among inflorescences of the same genet, or from the more indiscriminant foraging patterns of nectar-collecting bees (Galen \& Plowright, 1988). It is important to note, however, that estimates of the primary selfing rate are not without bias. For species with embryo competition (i.e. more fertilized ovules than can be supported), which may include E. angustifolium, this method will tend to overestimate the primary selfing rate (Lande $e t$ al., 1994). Also implicit in the estimate is the assumption that the relative fitnesses of selfed and outcrossed progeny in different fruits are comparable to their relative fitnesses in the same fruit. In fact, most estimates of inbreeding depression are based on the performance of self and outcross pollen in separate flowers, and therefore rest on the same assumption. Unfortunately, studies of the effects of self and outcrossed pollen in single versus mixed pollen loads have not been consistent in their findings (Bertin et al., 1989; Montalvo, 1992).

Because the low production of seeds by self-fertilization in E. angustifolium (13 per cent of outcrossed seed set, Table 1) may be a result of a physiological selfincompatibility or of inbreeding depression, it is important to distinguish these alternatives before interpreting our findings with regard to inbreeding depression. Self-incompatibility operates in the maternal tissue and is controlled by the maternal genotype and that of the pollen or pollen donor. Typically, incompatibility reactions occur at the stigmatic surface or in the style. Failure of pollen tubes in the ovules has been reported for some species (Kenrick et al., 1986; Scribailo \& Barrett, 1991; Broyles \& Wyatt, 1993) and has been interpreted as a form of late-acting self- 
incompatibility (Seavey \& Bawa, 1986). In contrast, inbreeding depression is a process acting in the zygote as a function of the zygote's genotype. Therefore inbreeding depression, caused by mutational load, typically occurs after fertilization and, because of variation in the mutation load among zygotes, it is usually variable in its magnitude and stage in development of expression (Seavey \& Carter, 1994). In E. angustifolium, we believe that low seed maturation in selfpollinations is a product of inbreeding depression, not incompatibility, because (1) seed-set varies among selfed individuals from 0 to 21 per cent (Fig. 1), (2) based on their size and appearance, unfilled ovules from selfed flowers failed at some point after fertilization, and (3) embryos failed at a wide range of stages. These observations are consistent with patterns of embryo failure in outcrossed flowers of $E$. angustifolium (Wiens et al., 1987) and with observations of embryo failure in self-pollinated flowers of $E$. angustifolium (S. Seavey, pers. comm) and E. obcordatum (Seavey \& Carter, 1994).

The population-level estimate of inbreeding depression for $E$. angustifolium is similar to the only other estimate for a diploid population of this species, which is 0.88 (J. Ågren, unpubl.). Such a strong negative impact of inbreeding is unusual among angiosperms. In fact, inbreeding depression in $E$. angustifolium is 1.8 times larger than the mean inbreeding depression for all outcrossed populations that have been examined to date $(\delta=0.53$, Husband $\&$ Schemske, 1995). Of the 38 angiosperm species for which similar life stages have been examined (reviewed in Husband \& Schemske, 1995), only one other species, Bidens sandivicensis (S. Schultz, unpubl.), has similar inbreeding depression $(\delta=0.94)$. The level of inbreeding depression in E. angustifolium is more similar to values reported for several gymnosperms (Snyder, 1968; Franklin, 1969; Sorenson \& Miles, 1974; Fowler \& Park, 1983), which range from 0.8 to 0.98 . One feature these species have in common is that they are long-lived woody or clonal perennials. Whether longlived angiosperms consistently exhibit such a high magnitude of inbreeding depression requires further study.

The high magnitude of inbreeding depression in this partially outcrossing population of E. angustifolium is qualitatively consistent with the theoretical expectation that outbred populations will contain more recessive or partially recessive lethal and deleterious mutations, and hence show more inbreeding depression, than inbred populations (Lande \& Schemske, 1985; Charlesworth \& Charlesworth, 1987). Inbreeding depression in $E$. angustifolium is about six times higher than in two highly autogamous congeners, E. collinum $(\delta=0.13$, J.
Ågren, unpubl.) and E. ciliatum $(\delta=0.16$, Parker et al., $1995)$. On a broader taxonomic scale, $E$. angustifolium has 4.1 times more inbreeding depression than the average of all self-fertilizing species examined to date (reviewed in Husband \& Schemske, 1995).

From a quantitative standpoint, the high inbreeding depression maintained in E. angustifolium is unusual, given the moderate levels of self-fertilization this population experiences. This is inconsistent with the theory (Lande \& Schemske, 1985; Charlesworth \& Charlesworth, 1987) which predicts that most inbreeding depression should be purged from populations with even moderate selfing. Lande et al. (1994) show, however, that with high mutation rates to recessive or partially dominant lethals, partially selfing populations can maintain very high inbreeding depression. Under such conditions purging of lethals through selfing fails to occur unless selfing rates exceed a critical threshold or there is sufficient variation in fitness of inbred progeny to allow some selfed individuals to survive to reproduce. It is possible that neither of these criteria is satisfied in E. angustifolium. Selfing rates may be close to 0.45 in $E$. angustifolium, but under some mutation rates, this may still by insufficient to purge lethals. In fact, cumulative fitnesses for selfed progeny among maternal parents are remarkably low and uniform (Fig. 2 ), suggesting that very few selfed progeny ever contribute to future generations. As a result, purging is unlikely, and inbreeding depression comparable to a strict outcrossing species will be maintained.

Fitnesses of outcrossed progeny at seed-set and germination exhibited not only a large variance among maternal plants but were also significantly correlated with the fitness of selfed progeny, such that maternal plants with high seed-set on outcrossing also exhibited high seed production in selfs. A positive correlation between self and outcross means may result from partially dominant mutations which will be expressed in both selfs and outcrosses, and/or maternal effects (Krebs \& Hancock, 1991). The experimental design used here does not allow us to distinguish between these alternatives, but it is likely that most of the correlation is the result of maternal effects. Evidence for this comes from the observation that the correlation is strongest at early life stages such as seed-set and germination, when maternal control is greatest (Roach \& Wulff, 1987), and is statistically insignificant at juvenile survival and biomass at 8 weeks. The role of maternal, rather than zygotic effects, in causing covariation between the relative fitness of selfs and outcrosses has been suggested for some species (Bishir \& Namkoong, 1987; Wolfe, 1993). Maternal influences on inbreeding depression caused by either maternal provisioning, cytoplasmic effects, or proportionally 
greater maternal contributions to endosperm could be examined by performing reciprocal crosses among parents (see Lynch, 1988).

Inbreeding depression in this species is not restricted to a single stage nor is it distributed evenly among life stages. Differences between selfed and outcrossed progeny were significant in each of the four life stages and stage-specific measures of inbreeding depression were statistically different from each other. Variation in inbreeding depression among stages has been detected in many studies (Schemske, 1983; Dudash, 1990; Johnston, 1992; Ågren \& Schemske, 1993), although no statistical comparison among stages has ever been made. Variation among stages is expected if different stages of development involve different genes or different numbers of genes that cause inbreeding depression. Thus, whether inbreeding depression at several stages can be purged at different rates upon inbreeding will depend on the genetic basis of early- vs. late-acting inbreeding depression and the degree to which stage-specific levels of inbreeding depression are genetically correlated (Husband \& Schemske, 1995). Correlations among inbreeding depression estimates at four life stages, across 34 families, indicated that inbreeding depression at one stage is independent of any other stage in $E$. angustifolium. Weak correlations among stages were reported from studies of Begonia hirsuta and B. semiovata (Ågren \& Schemske, 1993). These results suggest that inbreeding depression at each stage may be purged independently.

Most inbreeding depression in E. angustifolium occurs during seed maturation. Selfed progeny averaged 8.3 per cent seed set and outcrosses averaged 65.7 per cent. This is over three times the levels of lethality expressed at germination or juvenile survival. High levels of inbreeding depression during embryo development and seed maturation have been found in many other predominantly outcrossing species, particularly gymnosperms (Fowler, 1965a,b; Snyder, 1968; Franklin, 1969; Sorenson \& Miles, 1974; Fowler \& Park, 1983; Schemske, 1983; Park \& Fowler, 1984; Stevens \& Bourgourd, 1988; Karoly, 1991; reviewed in Husband \& Schemske, 1995). This pattern is consistent with the observation that lethality is usually concentrated during embryo development, when genes encoding many critical proteins are expressed for the first time (Meinke, 1991). Selfsterility in other species of Epilobium has also been attributed to lethality during embryo development (Seavey \& Carter, 1994). The question that remains is whether this inbreeding depression causing high selfsterility can be purged through high levels of selfing. Understanding the potential for evolutionary change will provide further insight into the genetic basis of inbreeding depression and the implications for mating system evolution in Epilobium.

\section{Acknowledgements}

We thank S. Curtis, J. Ross, M. Conrath and D. Ewing for technical assistance. This study was supported by a Royalty Research Fund grant to D.S. and a Postdoctoral Fellowship from the Natural Sciences and Engineering Research Council of Canada to B.H.

\section{References}

AGREN, J. AND SCHEMSKE, D. W. 1993. Outcrossing rate and inbreeding depression in two annual monoecious herbs, Begonia hirsuta and B. semiovata. Evolution, 47, $125-135$.

ASHMAN, T.-L. 1992. The relative importance of inbreeding and maternal sex in determining progeny fitness in Sidalcea oregana ssp. spicata, a gynodioecious plant. Evolution, 46, 1862-1874.

BERTIN, R. I., BARNES, C. AND GUTTMAN, S. I. 1989. Self-sterility and cryptic self-fertility in Campsis radicans (Bignoniaceae). Bot. Gaz., 150, 397-403.

BISHIR, J. AND NAMKOONG, G. 1987. Unsound seeds in conifers: estimation of numbers of lethal alleles and of magnitudes of effects associated with the maternal parent. Silvae Genet., 36, 180-185.

BRown, A. H. D. AND ALlARD, R. W. 1970. Estimation of the mating system in open-pollinated maize populations using isozyme polymorphisms. Genetics, 66, 133-145.

BROYLES, S. B. AND WYATT, R. 1993. The consequences of selfpollination in Asclepias exaltata, a self-incompatible milkweed. Am. J. Bot., 80, 41-44.

CHARLESWORTH, D. AND CHARLESWORTH, B. 1979. The evolutionary genetics of sexual systems in flowering plants. Proc. R. Soc. B, 205, 513-530.

CHARLESWORTH, D. AND CHARLESWORTH, B. 1987. Inbreeding depression and its evolutionary consequences. Ann. Rev. Ecol. Syst., 18, 237-268.

CHARLESWORTH, D., MORGAN, M. T. AND CHARLESWORTH, B. 1990. Inbreeding depression, genetic load, and the evolution of outcrossing rates in a multilocus system with no linkage. Evolution, 44, 1469-1489.

DARWIN, C. R. 1876. The Effects of Cross and Self-fertilization in the Vegetable Kingdom. John Murray, London.

DUDASH, M. R. 1990. Relative fitness of selfed and outcrossed progeny in a self-compatible protandrous species, Sabatia angularis L. (Gentianaceae): a comparison of three environments. Evolution, 44, 1129-1139.

FLINT, E. P. 1980. Ecology and Distribution of Diploid and Tetraploid Epilobium angustifolium (Fireweed) in the Beartooth Mountains of Wyoming and Montana. Ph.D. Thesis, Duke University.

FOWLER, D. P. AND PARK, Y. S. 1983. Population studies of white spruce. I. Effects of self-pollination. Can. J. Forest Res., 13, 1133-1138.

FOWLER, D. P. 1965 b. Effects of inbreeding in red pine, Pinus resinosa. Ait. IV. Comparison with other northeastern Pinus species. Silvae Genet., 14, 76-81. 
FOWLER, D. P. AND PARK, Y. S. 1983. Population studies of white spruce. I. Effects of self-pollination. Can. J. Forest Res., 13, 1133-1138.

FRANKLIN, E. C. 1969. Inbreeding depression in metrical traits of loblolly pine (Pinus taeda L.) as a result of self-pollination. Technical Rep. No. 40, School of Forest Resources, N. Carolina State Univ. Raleigh, 19 pp.

GALEN, C. AND PLowRIGHT, R. C. 1988. Contrasting movement patterns of nectar-collecting and pollen-collecting bumble bees (Bombus terricola) on fireweed (Chamaenerion angustifolium) inflorescences. Ecol. Entomol., 10, 9-17.

HALDANE, J. B. S. 1949. The association of characters as a result of inbreeding and linkage. Ann. Eugen., 15, 23.

HOLTSFORD, T. P. AND ELLSTRAND, N. C. 1990. Inbreeding effects in Clarkia tembloriensis (Onagraceae) populations with different natural outcrossing rates. Evolution, 44, 2031-2046.

HUSBAND, B. C. AND SCHEMSKE, D. W. 1995. Evolution of the magnitude and timing of inbreeding depression in plants. Evolution, in press.

JOHNSTON, M. O. 1992. Effects of cross and self-fertilization and progeny fitness in Lobelia cardinalis and L. siphilitica. Evolution, 46, 688-702.

JOHNSTON, M. O. AND SCHOEN, D. J. 1994. On the measurement of inbreeding depression. Evolution, in press.

KARoly, K. 1991. The Causes and Consequences of Intrapopulational Mating System Variation in Lupinus nanus (Leguminosae). Ph.D. Thesis, University of Chicago.

KENRICK, J., KAUL, v. AND wILlıAMS, E. G. 1986. Self-incompatibility in Acacia retinodes: site of pollen-tube arrest is the nucellus. Planta, 169, 245-250.

KIMURA, M. 1958. Zygotic frequencies in a partially self-fertilizing population. Ann. Report Nat. Instit. Genetics, Japan, 8, 104-105.

KREBS, S. L. AND HANCOCK, J. F. 1991. Embryonic genetic load in the highbush blueberry Vaccinium corymbosum (Ericaceae). Am. J. Bot., 78, 1427-1437.

LANDE, R. AND SCHEMSKE, D. W. 1985. The evolution of selffertilization and inbreeding depression in plants. I. Genetic models. Evolution, 39, 24-40.

LANDE, R., SCHEMSKE, D. W. AND SCHultz, s. T. 1994. High inbreeding depression, selective interference among loci, and the threshold selfing rate for purging recessive lethal mutations. Evolution, 48, 965-978.

LLOYD, D. G. 1979. Some reproductive factors affecting the selection of self-fertilization in plants. Am. Nat., 113, 67-79.

LYNCH, M. 1988. Design and analysis of experiments on random drift and inbreeding depression. Genetics, 120, 791-807.

MAKl, M. 1993. Outcrossing and fecundity advantage of females in gynodioecious Chionographis japonica var. kurohimensis (Liliaceae). Am. J. Bot., 80, 629-634.

MEINKE, D. W. 1991. Perspective on genetic analysis of plant embryogenesis. Pl. Cell, 3, 857-866.

MiLler, R. J., Jr. 1986. Beyond ANOVA, Basics of Applied Statistics. John Wiley and Sons, New York.

MONTALVO, A. M. 1992. Relative success of self and outcross pollen comparing mixed- and single-donor pollinations in Aquilegia caerulea. Evolution, 46, 1181-1198.

MOSQUIN, T. 1967. Evidence for autopolyploidy in Epilobium angustifolium (Onagraceae). Evolution, 21, 713-719.
PARK, Y. S. AND FOWLER, D. P. 1984. Inbreeding in black spruce (Picea mariana (Mill.) B.S.P.): self-fertility, genetic load, and performance. Can. J. Forest Res., 14, 17-21.

PARKER, 1. M., NAKAMURA, R. R. AND SCHEMSKE, D. W. 1995. Reproductive allocation and the fitness consequences of selfing in two sympatric species of Epilobium (Onagraceae) with contrasting mating systems. Am. J. Bot., in press.

RAVEN, P. H. 1979. A survey of reproductive biology in Onagraceae. N. Z. J. Bot., 17, 575-593.

RAVEN, P. H. 1988. Onagraceae as a model of plant evolution. In: Gottlieb, L. D. and Jain, S. K. (eds) Plant Evolutionary Biology, pp. 85-107. Chapman \& Hall, New York.

RITLAND, K. 1989. A series of FORTRAN computer programs for estimating plant mating systems. J. Hered., 81, 235-237.

RITLAND, K. AND JAIN, S. K. 1981. A model for the estimation of outcrossing rate and gene frequencies using $n$ independent loci. Heredity, 47, 35-52.

ROACH, D. A. AND WULFF, R. D. 1987. Maternal effects in plants. Ann. Rev. Ecol. Syst., 18, 209-235.

SCHEMSKE, D. w. 1983. Breeding system and habitat effects on fitness components in three neotropical Costus (Zingiberaceae). Evolution, 37, 523-539.

SCHOEN, D. J. 1983. Relative fitnesses of selfed and outcrossed progeny in Gilia achilleifolia (Polemoniaceae). Evolution, 37, 292-301.

SCHOEN, D. J. AND CLEGG, M. T. 1984. Estimation of mating parameters when outcrossing events are correlated. Proc. Natl. Acad.Sci. U.S.A., 81, 5258-5262.

SCRIBAILo, R. W. AND BARRETT, S. C. H. 1991. Pollen-pistil interactions in tristylous Pontederia sagittata (Pontederiaceae). II. Patterns of pollen tube growth. Am. J. Bot., 78, 1662-1682.

SEAVEY, S. R. AND BAWA, K. s. 1986. Late-acting self-incompatibility in angiosperms. Bot. Rev., 52, 195-219.

SEAVEY, S. R. AND CARTER, S. K. 1994. Self-sterility in Epilobium obcordatum (Onagraceae). Am. J. Bot., 81, 331-338.

SNYDER, E. B. 1968 . Seed yield and nursery performance of self-pollinated pines. Forest Sci., 14, 68-74.

SOKAL, R. R. AND ROHLF, F. J. 1981. Biometry, 2nd edn. Freeman and Co., New York.

SOLTIS, D. E., HAUFLER, C. H., DARROW, D. C. AND GASTONY, G. J. 1983. Starch gel electrophoresis of ferns: a compilation of grinding buffers, gel and electrode buffers and staining schedules. Am. Fern. J., 73, 9-27.

SORENSEN, F. C. AND MILES, R. S. 1974. Self-pollination effects on Douglas-fir and ponderosa pine seeds and seedlings. Silvae Genet., 23, 135-138.

STEVENS, J. P. AND BOUGOURD, S. M. 1988. Inbreeding depression and the outcrossing rate in natural populations of Allium schoenoprasum L. Heredity, 60, 257-261.

TOPPINGS, P. 1989. The Significance of Inbreeding Depression to the Evolution of Self-fertilization in Eichhornia paniculata (Spreng.) Solms. (Pontederiaceae) M.Sc. Thesis, University of Toronto, Canada.

WIENS, D., CALVIN, C. L., Wilson, C. A., DAVERN, C. 1., FRANK, D. AND SEAVEY, S. R. 1987. Reproductive success, spontaneous embryo abortion and genetic load in flowering plants. Oecologia, 71, 501-509.

wolFE, L. M. 1993. Inbreeding depression in Hydrophyllum appendiculatum: role of maternal effects, crowding and parental mating history. Evolution, 47, 374-386. 